\title{
Registro recente, redução de distribuição e atuais ameaças ao veado-campeiro Ozotoceros bezoarticus (Mammalia, Cervidae) no Estado de Santa Catarina, Brasil
}

\author{
Marcelo Mazzolli* \\ Rodrigo C. Benedet \\ Projeto Puma, R. Cristiano Brascher, 2080, CEP 88504-301 Lages - SC, Brasil \\ *Autor para correspondência \\ marcelo_puma@yahoo.com
}

Submetido em 01/08/2008

Aceito para publicação em 25/02/2009

\section{Resumo}

Os campos naturais localizados na microrregião de Lages são o hábitat natural do veado-campeiro, e a localidade de Coxilha Rica, conhecida por seus campos limpos, o seu maior refúgio no Estado de Santa Catarina. Registros recentes e inéditos de veado-campeiro neste Estado são aqui publicados pela primeira vez, bem como evidências de redução de sua distribuição histórica nesta região. Em um ambiente campestre crescentemente invadido por plantios de espécies exóticas, parcelamento da terra, e queima dos campos, o manejo adequado dos locais onde o veado-campeiro ainda persiste pode ser decisivo para a continuidade de suas populações remanescentes.

Unitermos: campos nativos, Coxilha Rica, reflorestamento, veado-campeiro, Ozotoceros bezoarticus

\section{Abstract}

Recent records, range loss, and current threats to the pampas deer Ozotoceros bezoarticus (Mammalia, Cervidae) in the state of Santa Catarina, Brazil. The native grasslands in the micro-region of Lages are the natural habitat of the pampas deer, and the locality of Coxilha Rica, known for its short grass, is its largest refuge in the state of Santa Catarina. Recent novel records of the pampas deer in this state are published here for the first time, as well as evidence of a reduction in its historical distribution. In a grassland environment that is increasingly invaded by plantations of exotic species, partition of land, and burning of grasslands, adequate management of the areas where the pampas deer still persist may be decisive for the survival of remaining populations.

Key words: Coxilha Rica, forest plantation, native grasslands, pampas deer, Ozotoceros bezoarticus 


\section{Introdução}

O veado campeiro Ozotoceros bezoarticus (Linnaeus, 1758) é um cervídeo considerado de grande tamanho para os padrões sul-americanos, exibe hábitos diurnos, e ocupa áreas abertas. Por estas razões pode ser registrado com certa facilidade nos locais onde habita. Apesar disto, a presença recente do veado-campeiro no Estado de Santa Catarina tem passado desapercebida (e.g., Merino et al., 1997; Cherem et al., 2004; Cáceres et al., 2007).

Os registros históricos sobre a espécie, disponíveis na literatura, não têm detalhado o seu status populacional nos locais de ocorrência, tornando-os menos informativos para subsidiar planos de ação e listas de espécies ameaçadas atualizadas.

Este trabalho é o primeiro que registra o veadocampeiro de forma sistemática no Estado de Santa Catarina, revelando a presença de uma população reprodutivamente ativa. Além disso, são apresentadas evidências de redução de distribuição como resultado de extinção local.

\section{Material e Métodos}

\section{Área de estudo}

A região de interesse está politicamente delimitada pela micro-região de Lages, com área de $15.570 \mathrm{~km}^{2}$ (SEPLAN, 1991). A vegetação é dominada pela Floresta Ombrófila Mista, também chamada de Floresta com Araucárias, e considerada por alguns autores como uma ecorregião da Mata Atlântica (e.g., Dinerstein et al., 1995).

A cobertura florestal da área de estudo manteve um aspecto secundário avançado, principalmente determinado pela presença de araucárias adultas, mas raramente antigas. Há indicativos de que a vegetação de campo seja remanescente de um período com clima mais seco (ver Pillar e Quadros, 1997).

A cobertura campestre apresenta uma mistura de campos limpo e sujo. O campo limpo domina na porção sul (especialmente na Coxilha Rica), favorecido pelos solos rasos, representado principalmente pela espécie Schizachyrium tenerum. A Coxilha Rica estende-se do Rio Pelotinhas a leste até o Rio Lava-Tudo, e ao sul até onde o campo encontra as florestas que cobrem o vale do Rio Pelotas.

Na porção norte predominam os solos profundos de origem basáltica e os campos sujos com Baccharis spp. e Paspalum notatum (Gomes et al., 1989), e onde o ambiente florestal é favorecido.

\section{Amostragem}

Registros oportunísticos da presença do veadocampeiro foram obtidos durante estudos de doutorado do primeiro autor no período entre 2003 e 2005 (Mazzolli, 2006), e pelo segundo autor durante campanhas para classificação da vegetação e inventariamento de fauna nos locais destinados à construção de usinas hidreléticas na Coxilha Rica durante os anos de 2005 e 2006 (SDR, 2006a e 2006b) e 2006 e 2007 para implantação de uma Área de Proteção Ambiental (SDR, 2007).

Campanhas intensivas para registro da presença de veados-campeiros foram realizadas durante dez meses na localidade de Coxilha Rica, entre julho de 2007 e abril de 2008, especialmente na Fazenda Três Capões de propriedade da empresa Gerdau, onde Pinus spp. foram plantados entre outubro de 2005 e dezembro de 2006.

Ao total foram realizadas dez saídas a campo programadas a cada 15 dias. Utilizou-se um GPS para marcar as trilhas percorridas e marcar os pontos de interesse.

\section{Resultados}

Durante as amostragens oportunísticas, entre o período 2003 a 2007, o veado-campeiro foi avistado em doze ocasiões, além de ter sido registrado com base em crânios em outras três ocasiões (dois históricos e um recente). Registros de sua distribuição histórica recente foram obtidas na Fazenda da Chapada Bonita e na Fazenda Dourado, onde atualmente já não habitam (Tabela 1). 
TABELA 1: Registros de veado-campeiro no Planalto Catarinense. Registros históricos são aqueles onde há apenas evidência de que a espécie habitava a área no passado, baseados em registro de crânio e depoimentos. Coordenadas estão em UTM datum SAD69. Evidências de reprodução foram baseadas em observação de filhotes.

\begin{tabular}{lllccc}
\hline \multicolumn{1}{c}{ Local de registro } & \multicolumn{1}{c}{ Ocorrência } & \multicolumn{1}{c}{$\begin{array}{c}\text { Ano da } \\
\text { observação }\end{array}$} & X & Y & $\begin{array}{c}\text { Evidência de } \\
\text { reprodução }\end{array}$ \\
\hline Faz. Chapada Bonita* & histórica $( \pm 10$ anos $)$ & 2004 & 576607 & 6910784 & - \\
Faz. Dourado* & histórica $( \pm 10$ anos $)$ & 2004 & 571419 & 6911165 & - \\
Faz. Luiz Camargo & atual & 2004 & 566402 & 6901628 & sim \\
Faz. Nelson Camargo & atual & 2004 & 570256 & 6888181 & não \\
Faz. Santa Ignês & atual & $2006-2007$ & 573575 & 6895031 & não \\
Faz. Nelson Araújo & atual & $2006-2007$ & 578252 & 6893845 & sim \\
Faz. Nelson Araújo & atual & $2006-2007$ & 576161 & 6843343 & não \\
Desconhecido & atual & $2006-2007$ & 574108 & 6842066 & não \\
Faz. Limoeiro & atual & $2006-2007$ & 546172 & 6863487 & sim \\
Faz. Limoeiro & atual & $2006-2007$ & 546751 & 6862474 & não \\
Faz. Limoeiro & atual & $2006-2007$ & 540931 & 6863807 & não \\
Faz. Três Capões & atual & $2007-2008$ & 564000 & 6879000 & sim \\
Município de Painel* & atual & Coletado em & - & - & -
\end{tabular}

* Registros baseados em observação de crânios. O único crânio coletado tem como origem o município de Painel (sem coordenada precisa), o qual encontra-se depositado no Laboratório de Ecologia da Universidade do Planalto Catarinense (UNIPLAC).

Os registros de veado-campeiro foram obtidos ao longo de uma extensão de mais de $50 \mathrm{~km}$ em um eixo norte-sul, no município de Lages, localizado no Planalto Catarinense (Figura 1). Evidências da presença do veado-campeiro nos municípios vizinhos de Otacílio Costa (norte de Lages) e Campo Belo do Sul não foram encontradas pelos autores, indicando ausência ou baixa densidade. Por outro lado, registrou-se a presença o veado-campeiro durante este estudo entre os Rios Pelotinhas e Lava-Tudo, onde a espécie não havia sido detectada em estudos prévios de EIA/RIMA.

Durante a amostragem intensiva foi possível registrar 25 indivíduos de veado-campeiro por avistamento, alguns deles em plantios novos de Pinus spp. (Figura 2). Durante as amostragens mais recentes, os veados foram detectados somente junto a banhados. Não foi possível verificar se a razão disto foi o abandono das áreas de plantios, ou se os veados ainda utilizavam os plantios mas não foram registrados por obliteração do campo de visão após o crescimento e adensamento dos plantios.

Apesar da amostragem ter sido concentrada na área da Coxilha Rica, no município de Lages, é possível que grupos significativos de veado-campeiro ainda habitem áreas contíguas nos municípios de Painel e São Joaquim. Com base na ausência de evidências em áreas vizinhas, mesmo algumas destas tendo sido investigadas pelos autores, é improvável que existam outras áreas no Estado de Santa Catarina muito além da Coxilha Rica e arredores com maior concentração de veados-campeiros. O campo limpo da Coxilha Rica parece ter favorecido a sobrevivência das populações de veado-campeiro, ao passo que em áreas de solo mais profundo e maior tendência florestal, localizadas ao norte do planalto Catarinense, o veado-campeiro aparentemente encontrase numericamente reduzido ou ausente. 


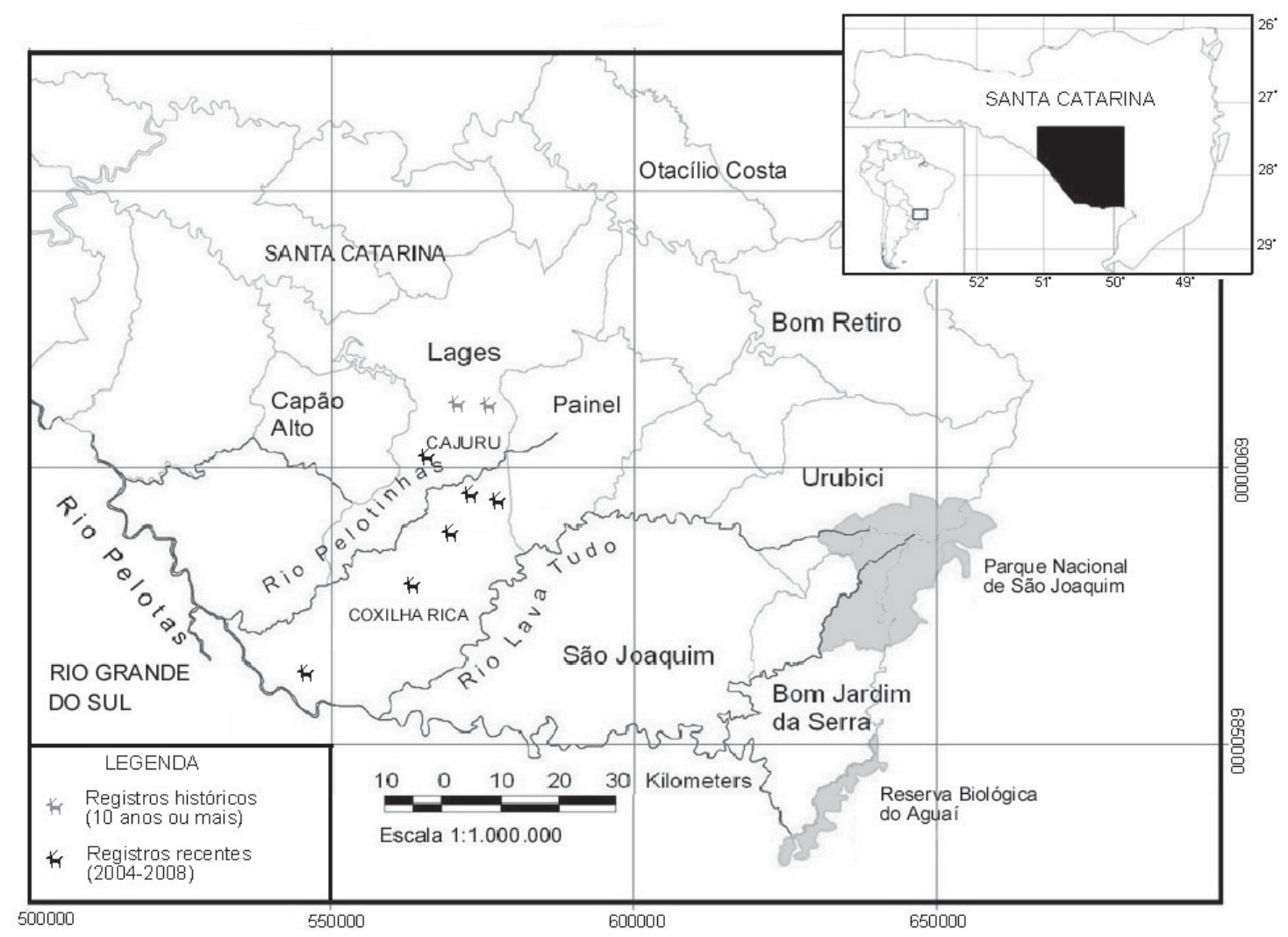

FIGURA 1: Mapa parcial do Planalto Catarinense (microrregião de Lages) destacando os locais de registro histórico e recente de veadocampeiro.

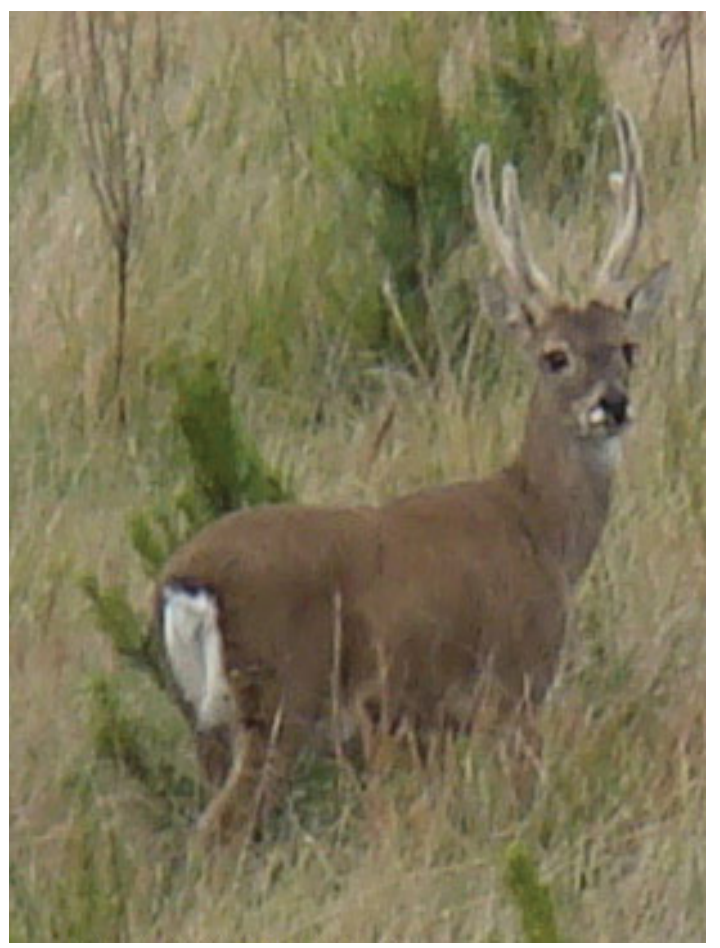

FIGURA 2: Macho de veado-campeiro (Ozotocerus bezoarticus), com chifres em fase final de crescimento, localizado em área de pinheiros jovens plantados sobre o campo nativo, na Coxilha Rica (Lages), em 20/09/2007. Crédito: Wilian R. Veronezi . 


\section{Discussão}

Depoimentos e registros eventuais por terceiros indicam que a distribuição do veado-campeiro estende-se atualmente até Otacílio Costa e Bom Jardim da Serra. Mas estes depoimentos adicionais, somados ao reduzido registro na literatura até o momento, apontam também para uma drástica redução numérica da espécie nestas áreas.

Evidências factuais da redução na distribuição do veado-campeiro foram obtidas neste estudo mesmo em áreas próximas à Coxilha Rica. $\mathrm{O}$ veado-campeiro foi extinto de duas das áreas amostradas a aproximadamente 10 anos passados, sendo que as únicas evidências obtidas de sua presença histórica foram o registro de crânios mantidos como troféus em fazendas rurais da região.

A situação de declínio do veado-campeiro na área de estudo parece seguir o padrão de áreas adjacentes de sua distribuição. No estado vizinho do Paraná, onde o veado-campeiro era antes amplamente distribuído, encontra-se agora confinado a populações remanescentes isoladas e geneticamente diferentes de outras populações do Brasil, Argentina, Paraguai e Uruguai (Braga et al., 2005), sendo por isto considerado ameaçado de extinção neste estado (Margarido e Braga, 2004). Também no Paraná o veado-campeiro foi observado alimentando-se de espécies forrageiras em campos agriculturáveis (Braga et al., 2000). Este comportamento sugere que a espécie até certo ponto possa tolerar alterações antrópicas, e que talvez não seja este o motivo exato de seu declínio numérico. A vegetação dominante na nossa área de estudo são os campos naturais, com poucos plantios de forrageiras, de maneira que aqui o veado-campeiro deve estar alimentando-se principalmente de espécies nativas. Mesmo assim, a espécie parece estar sofrendo um processo de redução em sua distribuição.

O declínio do veado-campeiro de forma mais abrangente no planalto Catarinense e sua extinção localizada em parte da área de estudo estão certamente relacionadas com a caça ilegal, manejo (biológico) inadequado de propriedades rurais, parcelamento da propriedade rural, e inexistência de áreas protegidas para a espécie.

Os plantios de Pinus spp. vêm avançando rapidamente sobre as áreas campestres naturais do sul do Brasil, sem que estudos de impacto ambiental (EIA/ RIMA) sejam conduzidos, como prevê a constituição (Pillar et al., 2006). Os veados-campeiros têm hábito eminentemente campestre, portanto os plantios de espécies florestais exóticas sobre o campo nativo inutilizam o hábitat para a espécie. O problema é exacerbado pela falta de mecanismos legais e administrativos que exijam a averbação de reservas legais que incluam áreas campestres.

Além dos florestamentos com espécies exóticas, os veados campeiros enfrentam o manejo inadequado dos campos. Na área de estudo, os veados procuram refugiar-se em banhados durante a queima dos campos, mas mesmo os banhados estão sujeitos à ação do fogo. Na Fazenda Três Capões, onde foram realizadas as observações mais intensivas, o encarregado resgatou vários filhotes de veado-campeiro durante a queima de um dos principais banhados da propriedade, em outubro de 2007, que de outra forma seriam alcançados pelo fogo. Isto demonstra a importância de controlar a queima para que não atinja os banhados.

Como forma de manejo para manter as populações de veado, recomenda-se a implementação de estudos de impacto ambiental e monitoramento em florestas plantadas, evitar a queima e drenagem de banhados, e delimitação de áreas de reserva legal em parcelas de campo, preferivelmente no entorno de banhados para que haja continuidade de ambientes remanescentes para o veado-campeiro e outras espécies campestres. É preciso também prever Unidades de Conservação (UC) que abriguem as populações remanescentes de veadocampeiro na Coxilha Rica.

\section{Agradecimentos}

Agradecemos o suporte financeiro da empresa Seiva, subsidiária da Gerdau, e da empresa Florestal Gateados localizada em Campo Belo do Sul.

\section{Referências}

Braga, F. G.; González, S.; Maldonado, J. E. 2005. Survey of Ozotoceros bezoarticus at Parana State, Brazil. Deer Specialist Group News, Montevidéu, Uruguay, p.2-4. 
Braga, F. G. ; Moura-Britto, M.; Margarido, T. C. C. 2000. Estudo de uma população relictual de veado-campeiro, Ozotoceros bezoarticus (Linnaeus) (Artiodactyla: Cervidae) no município da Lapa, Paraná, Brasil. Revista Brasileira de Zoologia, 17 (1): 175181.

Cáceres, N. C.; Cherem, J. J.; Graipel, M. E. 2007. Distribuição geográfica de mamíferos terrestres na região Sul do Brasil. Ciência \& Ambiente, 35: 167-180.

Cherem, J. J.; Simões-Lopes, P. C.; Althoff, S.; Graipel, M. E. 2004. Lista dos mamíferos do Estado de Santa Catarina, sul do Brasil. Mastozoologia Neotropical, 11 (2): 151-184.

Dinerstein, E.; Olson D. M.; Graham D. J.; Webster, A. L.; Primm, S. A.; Bookbinder, M. P.; Ledec, G. 1995. A conservation assessment of the terrestrial ecoregions of Latin America and the Caribbean. The World Bank, Washington, USA, 128pp.

Gomes, K. E.; Quadros, J. L. F.; Quadros, F. L. F.; Vidor, M. A.; Dall'Agnol, M.; Ribeiro, A. M. L. 1989. Zoneamento das pastagens naturais do Planalto Catarinense. XI Reunião do Grupo Técnico Regional do Cone Sul em Melhoramento e Utilização dos Recursos Forrageiros das Áreas Tropical e Subtropical, Lages, Brasil, p.304-314.

Margarido, T. C. C.; F. G. Braga. 2004. Mamíferos. In: Mikich, S. B. \& Bernils, R. S. (Eds). Livro vermelho da fauna ameaçada no estado do Paraná. Governo do Estado do Paraná (IAP, SEMA), Curitiba, Brasil, p.27-137.

Mazzolli, M. 2006. Persistência e riqueza de mamíferos focais em sistemas agropecuários no planalto meridional brasileiro. Tese de Doutorado, Universidade Federal do Rio Grande do Sul, Brasil, 108pp.
Merino, M. L.; Gonzales, S.; Leeuwenberg, F.; Rodrigues, F. H. G.; Pinder, L.; Tomás, W. M. 1997. Veado campeiro (Ozotoceros bezoarticus Linnaeus 1758): Distribuição, história natural, ecologia e conservação. In: Duarte, J. M. B. (Ed.). Biologia e conservação dos cervídeos Sul-Americanos. Fundação de Estudos e Pesquisas em Agronomia, Medicina Veterinária e Zootecnia, Jaboticabal, São Paulo, Brasil, p. 42-58.

Pillar, V. D.; Boldrini I. I.; Hasenack, H.; Jacques, A. V. A.; Both, R.; Müller, S. C.; Eggers, L.; Fidelis, A.; Santos, M. M. G.; Oliveira, J. M.; Cerveira, J.; Blanco, C.; Joner, F.; Cordeiro, J. L.; Pinillos Galindo, M. 2006. Workshop Estado Atual e Desafios para a Conservação dos Campos. Disponível em $<$ http://ecoqua. ecologia.ufrgs.br>. Acesso em 14 de julho de 2007.

Pillar, V.de P.; Quadros, F. L. F. 1997. Grassland-forest boundaries in southern Brazil. Coenoses, 12 (2-3): 119-126.

SDR. 2006a. Avaliação ambiental dos impactos ambientais das PCH's - Bacia do Rio Lava Tudo. Secretaria de Estado do Desenvolvimento Regional - Projetos Especiais. Governo do Estado de Santa Catarina, Lages, Brasil, 259pp.

SDR. 2006b. Avaliação ambiental dos impactos ambientais das PCH's - Bacia do Rio Pelotinhas. Secretaria de Estado do Desenvolvimento Regional - Projetos Especiais. Governo do Estado de Santa Catarina, Lages, Brasil, 264pp.

SDR. 2007. Proposta de criação da Área de Preservação Ambiental Coxilha Rica. Secretaria de Estado do Desenvolvimento Regional - Projetos Especiais. Governo do Estado de Santa Catarina, Lages, Brasil, 422pp.

SEPLAN. 1991. Atlas escolar de Santa Catarina. Secretaria de Estado de Coordenação Geral e Planejamento, Sub-secretaria de Estudos Geográficos e Estatísticos, Florianópolis, Brasil, 135pp. 